\title{
$5-2012$
}

\section{A Double Cantilever Beam Specimen for Foam Core Fracture Characterization}

\author{
Elio E. Saenz \\ Florida Atlantic University \\ Adrián Hernández-Pérez \\ Leif A. Carlsson \\ Florida Atlantic University \\ Anette M. Karlsson \\ Cleveland State University, a.karlsson@csuohio.edu
}

Follow this and additional works at: https://engagedscholarship.csuohio.edu/enme_facpub

Part of the Mechanical Engineering Commons

How does access to this work benefit you? Let us know!

\section{Original Citation}

Saenz, E. E., Hernández-Pérez, A., Carlsson, L. A., 2012, "A Double Cantilever Beam Specimen for Foam Core Fracture Characterization," Journal of Sandwich Structures \& Materials, 14(3) pp. 281-295.

This Article is brought to you for free and open access by the Mechanical Engineering Department at EngagedScholarship@CSU. It has been accepted for inclusion in Mechanical Engineering Faculty Publications by an authorized administrator of EngagedScholarship@CSU. For more information, please contact library.es@csuohio.edu. 


\title{
A double cantilever beam specimen for foam core fracture characterization
}

\author{
Elio E Saenz', Adrián Hernández-Pérez², \\ Leif A Carlsson' and Anette M Karlsson ${ }^{3}$
}

\begin{abstract}
This article presents the analysis and test results for a new sandwich double cantilever beam specimen for foam fracture characterization. The foam is sandwiched between two stiff and strong aluminum adherends. The specimen is analyzed using a modified version of the classical Kanninen elastic foundation model. Finite element analysis is conducted to determine the stress state near the crack tip and compliance of the double cantilever beam sandwich specimen. Model predictions are compared to experimental compliance data and crack growth paths for double cantilever beam specimens with polyvinyl chloride and polyethersulfone foams. The elastic foundation model and finite element analysis compliance results were in close agreement with experimental data over a range of crack lengths. The experiments revealed crack kinking for double cantilever beam specimens with $25.4 \mathrm{~mm}$ thick cores, whereas the crack path was stable in specimens with thinner $(12.7 \mathrm{~mm})$ cores. The distributions of T-stress ahead of the crack tip indicate crack instability for thicker cores while thinner cores promote stable growth, in agreement with experimentally observed crack paths. Hence thinner foam cores should be considered when conducting fracture testing of foam cores. An expression for the minimum admissible length of the uncracked specimen region was determined from the foundation model.
\end{abstract}

\section{Keywords}

double cantilever beam, crack kinking, elastic foundation model, finite element analysis

\footnotetext{
'Department of Ocean and Mechanical Engineering, Florida Atlantic University, Boca Raton, FL, USA

${ }^{2}$ Centro de Investigación Científica de Yucatán, A.C., Unidad de Materiales, Mérida, Yucatán, México

${ }^{3}$ Department of Mechanical Engineering, University of Delaware, Newark, DE, USA
}

Corresponding author:

Elio E Saenz, Department of Ocean and Mechanical Engineering, Florida Atlantic University, Boca Raton FL 3343I, USA

Email: esaenz@fau.edu 


\section{Introduction}

Sandwich composites with low density polymer foam cores are increasingly being utilized in lightweight structures. It is widely recognized that such foam cores typically are weak and brittle, and may govern failure of sandwich structures. Hence, improved test methods for determining the fracture resistance of polymer foams are required. The core fracture toughness is typically measured using the single-edge notch bend (SENB) specimen [1-4]. The SENB tests works properly for brittle foams such as cross-linked polymethacrylimide (PMI) and polyvinyl chloride (PVC) foams. Attempts to determine fracture toughness of ductile thermoplastic foams such as polyethersulfone (PES) by Saenz et al. [4] using the SENB specimen, however, were not successful. The specimens failed by yielding during flexure loading prior to any significant crack propagation. To avoid the undesired flexural failure mode of the PES foam test specimen, Saenz et al. [4] developed a symmetric sandwich double cantilever beam (DCB) specimen configuration with a core strip sandwiched between aluminum adherends. Fracture testing with this specimen, however, revealed that in some cases the crack did not propagate in a self-similar manner, but rather kinked up or down towards one of the aluminum adherends.

The kinking of a mode I crack was first considered by Cotterell and Rice [5]. They identified the importance of the so-called T-stress on the stability of cracks subject to mode I loading. The T-stress is a local stress, nonsingular acting parallel to the crack plane [5] first identified by Williams [6]. Cotterell and Rice [5] suggested that the crack is directionally stable if the T-stress ahead of the tip is negative, and that the crack is directionally unstable when the T-stress is positive. Chen and Dillard [7] conducted finite element stress analysis of aluminum/epoxy adhesive DCB specimens. Based on the distribution of T-stress, they suggested that self-similar stable crack propagation should be more likely to occur in specimens with thin adhesive layers than in specimens with thick adhesive layers.

In this study, the previously introduced symmetric sandwich DCB specimen [4] is considered at some detail. The specimen, Figure 1, consists of a foam
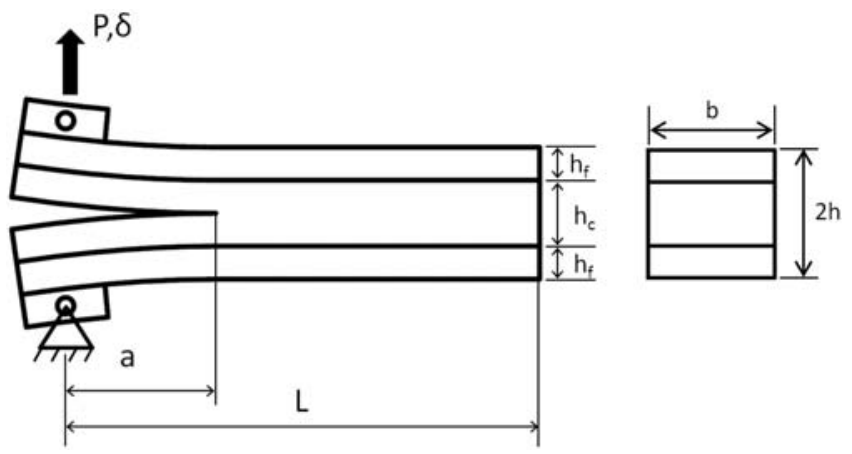

Figure I. Symmetric sandwich DCB specimen.

DCB: double cantilever beam. 
core adhesively bonded to aluminum adherends. A crack is introduced at the midplane of the core at the loaded end of the specimen. The elastic foundation model originally proposed for solid aluminum DCB specimens by Kanninen [8] is applied. Furthermore, the T-stress near the crack tip will be determined using finite element analysis. The model results will be compared to experimentally determined compliance data and crack paths observed.

\section{Analysis}

\section{Elastic foundation model}

Kanninen [8] showed that a homogeneous isotropic DCB specimen can be modeled as two cantilevered beams joined by an elastic Winkler foundation. The sandwich DCB specimen considered here, Figure 1, consisting of two aluminum adherends bonded to a foam core, is represented by an elastic foundation model as shown in Figure 2. The compliance, $C$, of the DCB specimen defined by the displacement of the upper load application point, $\delta$, divided by the applied load, $P$, is given by the following expression [8]

$$
C=\frac{4}{E_{x} b h^{3} \lambda^{3}}\left[2 \lambda^{3} a^{3}+3 \lambda a F_{1}+3 F_{2}\right]
$$

where

$$
F_{1}=\left[\frac{\sinh ^{2}(\lambda c)+\sin ^{2}(\lambda c)}{\sinh ^{2}(\lambda c)-\sin ^{2}(\lambda c)}\right]+2 \mathrm{a} \lambda\left[\frac{\sinh (\lambda c) \cosh (\lambda c)+\sin (\lambda c) \cos (\lambda c)}{\sinh ^{2}(\lambda c)-\sin ^{2}(\lambda c)}\right] \quad(2 \mathrm{a}) \leftarrow
$$

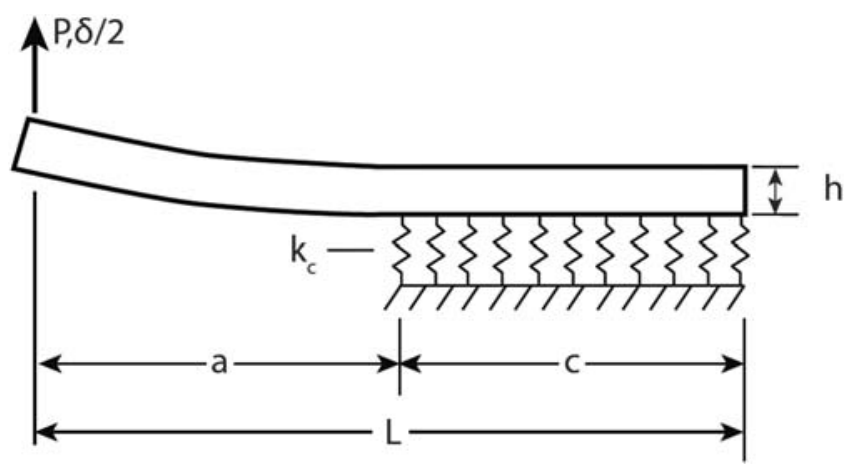

Figure 2. Modified Kanninen model of symmetric sandwich DCB specimen. DCB: double cantilever beam. 


$$
F_{2}=\frac{\sinh (\ll) \cosh (\ll)-\sin (\ll) \cos (\ll)}{\sinh ^{2}(\ll)-\sin ^{2}(\ll) \leftarrow} \leftarrow+\mathrm{a} \quad \frac{\sinh ^{2}(\ll)+\sin ^{2}(\ll)}{\sinh ^{2}(\ll)-\sin ^{2}(\ll)} \leftarrow
$$

$a$ is the crack length and $c=L \quad a$ is the length of the uncracked region of the specimen (Figure 2), $E_{x}$ is the effective flexural modulus of the legs of the specimen, $b$ is the specimen width, $h$ is half the specimen thickness $\left(h=h_{f}+h_{c} / 2\right)$ as shown in Figure 1 and is a dimensionless foundation parameter.

$$
=\left(\frac{3 k_{c}}{E_{x} b h^{3}}\right)^{1 / 4}
$$

where $k_{c}$ is the foundation modulus, given by

$$
k_{c}=\frac{2 E_{c} b}{h_{c}}
$$

For determination of $E_{x}$ it is recognized that each leg of the DCB sandwich specimen consists of the adherend and half the core. Laminated plate theory [9] is used to determine $E_{x}$, see Appendix for a detailed analysis.

$$
E_{x}=\frac{12}{d_{11} h^{3}}
$$

Here $d_{11}$ is the $m=n=1$ element of the bending compliance matrix (see Appendix).

\section{Fracture mechanics analysis}

Since the DCB specimen is symmetric and loaded symmetrically it is assumed that $K_{\mathrm{II}}=0$. According to Williams [6], the near crack tip stress field of an isotropic elastic material, with a crack loaded in mode I is given by

$$
\begin{gathered}
\sigma_{x}=\frac{K_{I}}{\sqrt{2 \pi r}} \cos \left(\frac{\theta}{2}\right) 1 \sin \left(\frac{\theta \psi}{2}\right) \sin \left(\frac{3 \theta}{2}\right)+T \\
\sigma_{y}=\frac{K_{I}}{\sqrt{2 \pi r}} \cos \left(\frac{\theta}{2}\right) 1+\sin \left(\frac{\theta}{2}\right) \sin \left(\frac{3 \theta \psi}{2}\right) \\
\tau_{x y}=\frac{K_{I}}{\sqrt{2 \pi r}} \cos \left(\frac{\theta}{2}\right) \sin \left(\frac{\theta \psi}{2}\right) \sin \left(\frac{3 \theta}{2}\right)
\end{gathered}
$$


where $r$ is the distance from the crack tip and $\theta$ is the angle from the $x$ axis (along the crack plane), see Figure $3 . K_{I}$ is the mode I stress intensity factor, and $T$ the T-stress acting parallel to the crack plane. The stress distribution ahead of the tip $(\theta=0)$ is of main concern. Substitution of $\theta=0$ into equations (6a) and (6b) yields the T-stress

$$
T=\sigma_{x} \quad \sigma_{y}
$$

Hence, the T-stress ahead the crack tip is given by the difference between the two (singular) normal stresses.

\section{Finite element analysis}

In order to determine the DCB specimen compliance and the distribution of T-stress near the crack tip, finite element analysis (FEA) was conducted. All FE models employed ANSYS 11.0 [10] with four-noded PLANE 42 elements configured in plane strain. FE models were also conducted using eight-noded PLANE 82 elements, but the results changed insignificantly. This element is a four-node quadrilateral element with translations in the nodal $x$ and $y$ directions, i.e. two degrees of freedom per node. Symmetric DCB specimens with $6.35 \mathrm{~mm}$ thick aluminum adherends and polymer foam cores were modeled (Figure 4). The elastic modulus and the Poisson's ratio of aluminum are $E=70 \mathrm{GPa}$ and $v_{f}=0.3$. Polymer foams considered in this study are cross-linked thermoset polyvinyl chloride (PVC) foams and amorphous ductile thermoplastic polyether sulfone (PES) foams. Three types of PVC foam cores (H45, H60 and H100) and three types of PES foam cores (F50, F90 and F130) manufactured by DIAB were analyzed. The elastic modulus of each foam is listed in Table 1 [4]. Poisson's ratio of the foams was assumed to be $v=0.32$. Core thicknesses $h_{c}=12.7$ and $25.4 \mathrm{~mm}$ were examined. The FEA model of the DCB specimens was $200 \mathrm{~mm}$ long $(L=200 \mathrm{~mm})$. The crack length, $a$, was varied from 5 to $150 \mathrm{~mm}$. For analysis of the T-stress, a crack length of $45 \mathrm{~mm}$ was used. The finite element model (for $a=25.4 \mathrm{~mm}$ thick core) used a regular mesh for the face sheets and core with elements of size $0.2 \times 0.2 \mathrm{~mm}^{2}$. Near the crack tip, the mesh was refined with elements of dimensions of

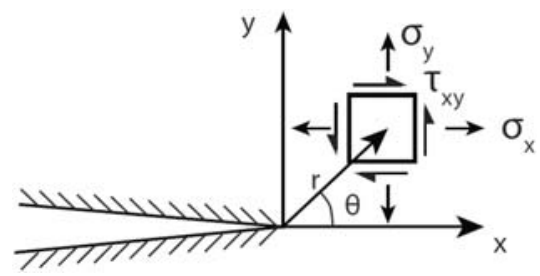

Figure 3. Stresses in an element near the crack tip. 
$0.025 \times 0.2 \mathrm{~mm}^{2}$. A total of 218,800 elements were used. A more refined mesh was investigated to establish the accuracy of the model, and since that yielded the same results, the mesh as defined was used. A load of $100 \mathrm{~N}$ per unit width $(P / b=100 \mathrm{~N} / \mathrm{m})$ was applied on the end node of the upper leg with the bottom end node fixed (Figure 4). Small deformations are assumed in the model. In order to prevent rigid body rotation of the model, the uncracked end of the DCB specimen was constrained from horizontal displacements at the midplane. The compliance, $C$, of the DCB specimen was determined from the vertical displacement, $\delta$, of the loading point on the upper leg divided by the applied load $P$, i.e. $C=\delta / P$.

\section{Experimental}

\section{Materials and test specimens}

PVC foam densities $45,60,100 \mathrm{~kg} / \mathrm{m}^{3}$ and PES foam densities $50,90,130 \mathrm{~kg} / \mathrm{m}^{3}$ obtained from DIAB were considered. DCB specimens were prepared from

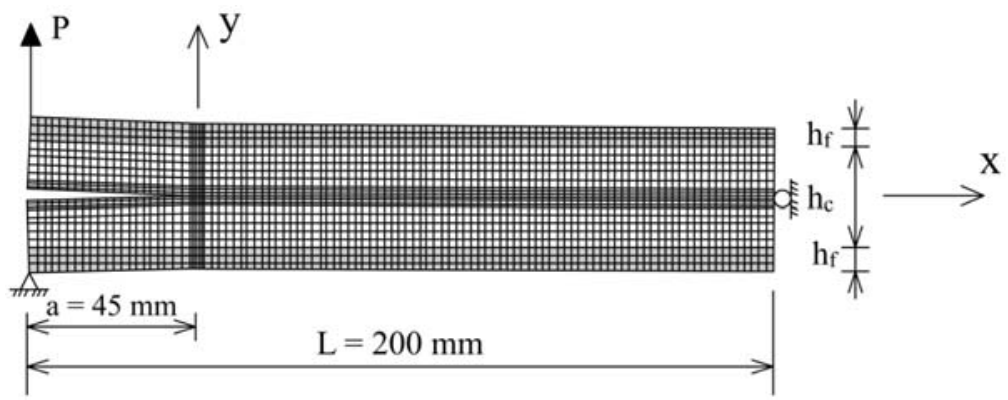

Figure 4. Schematic of finite element model of sandwich DCB specimen.

DCB: double cantilever beam.

Table I. Tensile modulus and minimum uncracked length, $c=c_{\min }$, for $D C B$ specimens with a $50 \mathrm{~mm}$ long crack and $12.7 \mathrm{~mm}$ thick core based on equation (I0) (I\% definition). Poisson's ratio for the foams was assumed to be $v=0.32$

\begin{tabular}{llcc}
\hline Foam & $E_{c}(\mathrm{MPa})$ & $\left(\mathrm{m}^{\mathrm{l}}\right)$ & $c_{\text {min }}(\mathrm{mm})$ \\
\hline PVC H45 & 33.1 & 30.6 & 86 \\
PVC H60 & 46.0 & 33.2 & 80 \\
PVC HI00 & 68.1 & 36.6 & 69 \\
PES F50 & 17.6 & 26.2 & 101 \\
PES F90 & 22.7 & 27.9 & 95 \\
PES FI30 & 66.1 & 36.4 & 73 \\
\hline
\end{tabular}


$6.25 \mathrm{~mm}$ thick aluminum adherends bonded to 12.7 and $25.4 \mathrm{~mm}$ thick PES cores. For the PVC foams, only specimens with $12.7 \mathrm{~mm}$ thick cores were prepared. The total length and width of the specimens were, $L=20 \mathrm{~cm}$ and $b=2.54 \mathrm{~cm}$ (Figure 2). The specimens were prepared as described by Saenz et al. [4] Figure 5 shows a typical sandwich DCB specimen with a $25.4 \mathrm{~mm}$ thick F90 core. Testing was conducted by application of load at a crosshead rate of $1.25 \mathrm{~mm} / \mathrm{min}$. Specifically, the crack was extended incrementally, and the DCB specimen compliance and critical load for crack propagation were determined at each crack length.

\section{Results and discussion}

Photographs of DCB sandwich specimens after crack propagation are shown in Figure 6. Figure 6(a) shows a DCB specimen with a $25.4 \mathrm{~mm}$ thick F90 core. As soon as the crack started to propagate, crack kinking occurred at a steep angle. The core crack transitioned into a face/core interface crack upon further load application. Prior to crack extension, the initially sharp crack front displayed blunting as a consequence of the ductile behavior of the thermoplastic PES foam. For the sandwich specimens with $12.7 \mathrm{~mm}$ thick PVC and PES cores, stable crack extension occurred along the center of the specimen thickness, see the example of a specimen with a $12.7 \mathrm{~mm}$ thick PVC H100 core shown in Figure 6(b).

Figure 7 shows a typical load-displacement records for DCB specimens with $12.7 \mathrm{~mm}$ thick H100 PVC and F130 PES foam cores. The first curve, designated by the dashed line, represents crack propagation from the razor blade sharpened initial crack tip. For both types of foam it was noted that some amount of stable crack propagation occurred during the first loading cycle. For the ductile PES foam, Figure 7(b), the non-linear response past the initiation of crack is also associated with crack tip blunting. The filled circle on each loading curve represents the visually observed onset of crack propagation defining the critical load and

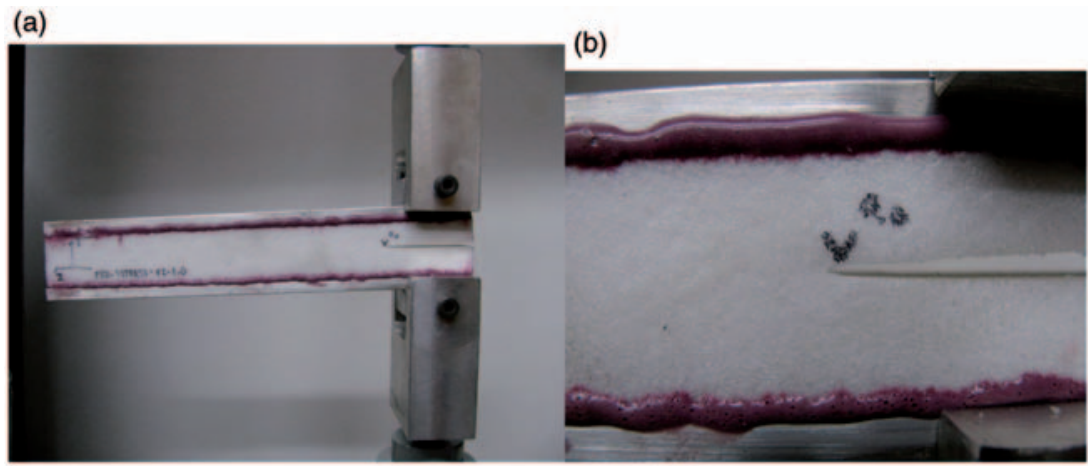

Figure 5. Sandwich DCB specimen with a $25.4 \mathrm{~mm}$ thick PES core prior to testing. DCB: double cantilever beam; PES: polyethersulfone. 
displacement $\left(P_{c}\right.$ and $\left.\delta_{c}\right)$. Crack propagation typically occurred in a stick-slip manner for the PVC cores.

Compliance predictions from the EFM, equation (1), and FEA were compared to experimentally measured compliance versus crack length curves for the sandwich DCB specimens. Figure 8 shows compliance results for all tested DCB specimens with $12.7 \mathrm{~mm}$ thick cores. The foundation model and FEA compliance predictions are overall in agreement with experimentially measured DCB compliance data for the PVC cores over a large range of crack lengths. For the F90 PES foam, however, Figure 8(e), the foundation model and FEA slightly underpredict the

(a)

(b)

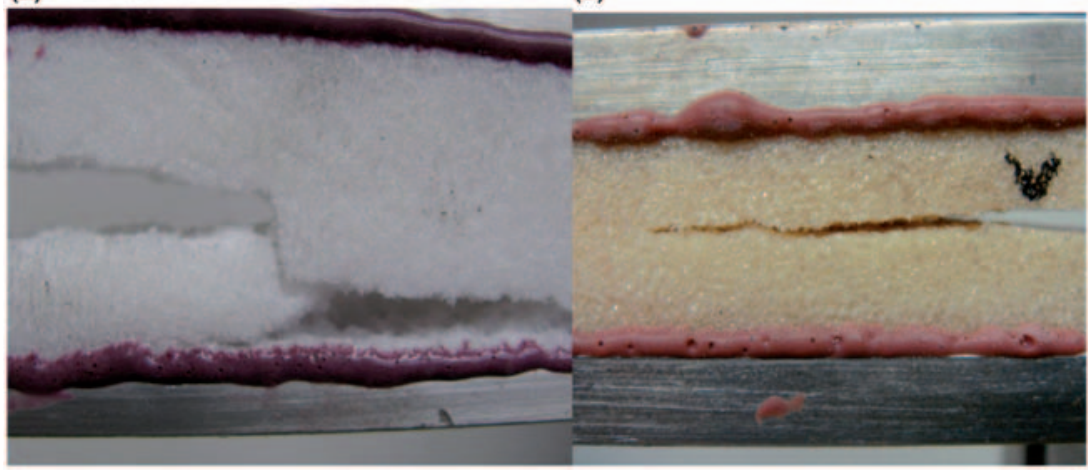

Figure 6. Photographs of crack growth in sandwich DCB specimens. (a) $25.4 \mathrm{~mm}$ PES F90 core, (b) $12.7 \mathrm{~mm}$ thick HIOO PVC core.

DCB: double cantilever beam; PES: polyethersulfone; PVC: polyvinyl chloride.
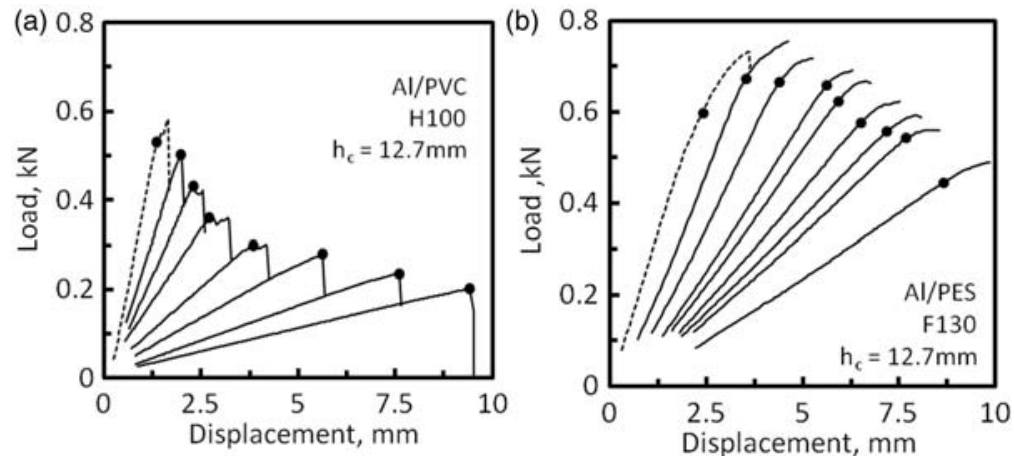

Figure 7. Load-displacement curves for DCB sandwich specimens. (a) HIO0 (PVC), (b) FI30 (PES).

DCB: double cantilever beam; PES: polyethersulfone; PVC: polyvinyl chloride. 
experimental compliance. The FEA and EFM predictions of the DCB specimen compliance agree closely.

\section{Crack path stability - T-stress results}

Figure 9 shows the distribution of T-stress ahead of the crack tip along the crack plane in DCB sandwich specimens with 12.7 and $25.4 \mathrm{~mm}$ thick PVC foam cores at a crack length $a=45 \mathrm{~mm}$. The T-stress behind the crack tip is not shown because it
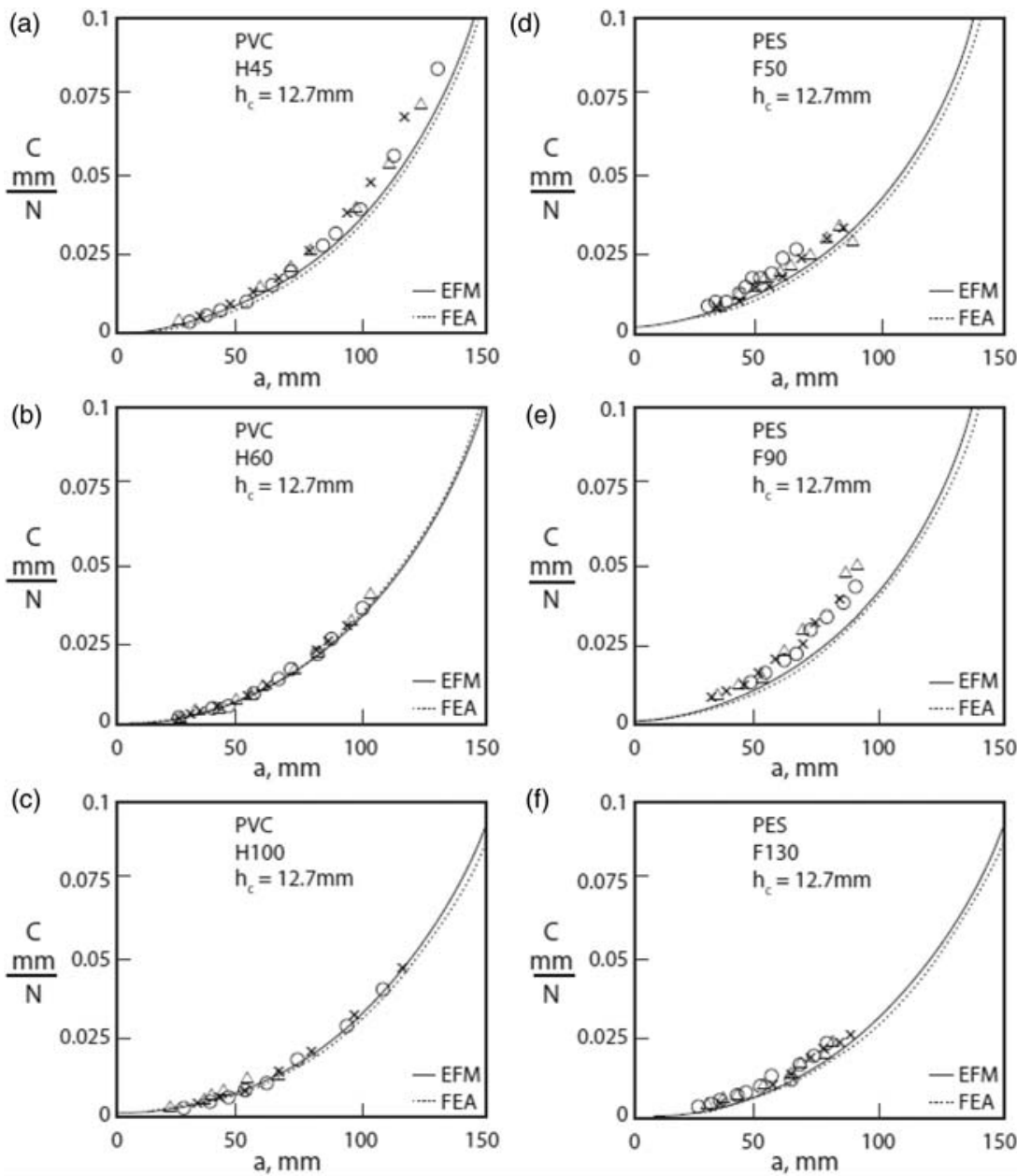

Figure 8. Compliance vs crack length curves for DCB sandwich specimens. (a) $\mathrm{H} 45$, (b) $\mathrm{H} 60$, (c) $\mathrm{HIO0}$, (d) F50, (e) F90, (f) FI30.

DCB: double cantilever beam. 

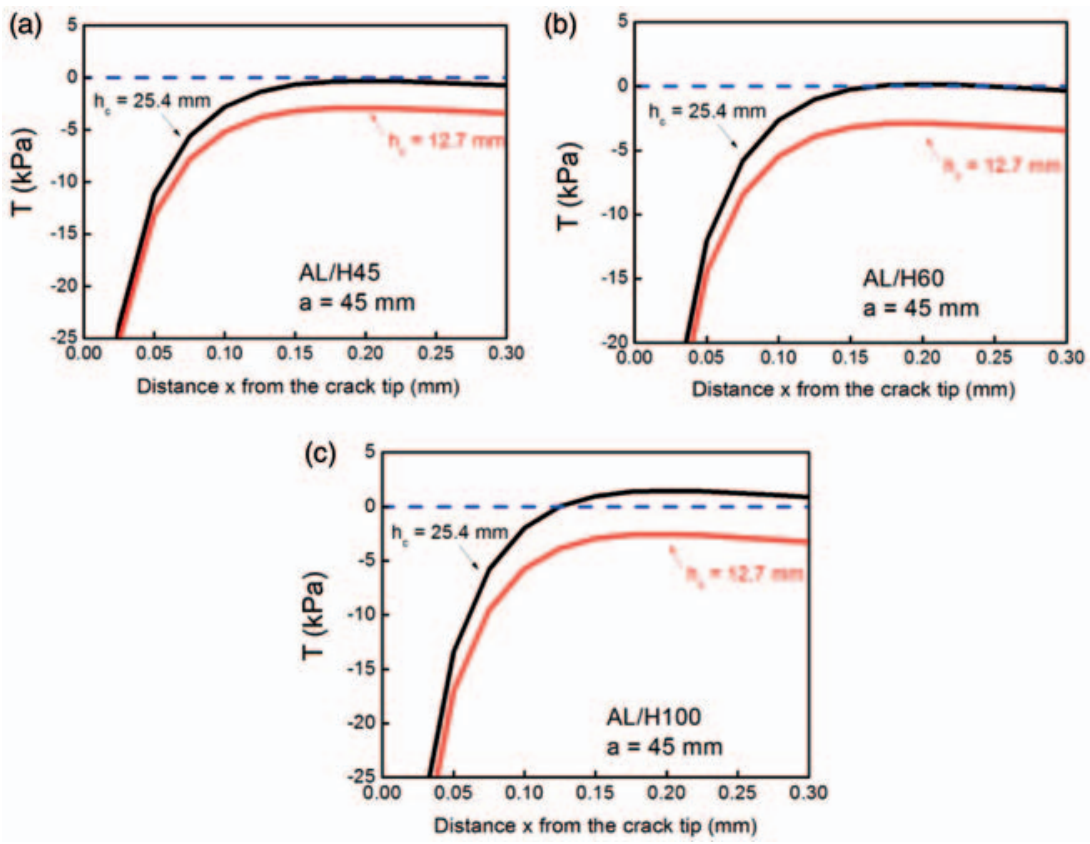

Figure 9. Distribution of T-stress along crack plane in DCB sandwich specimens. The load applied is, $P=100 \mathrm{~N} / \mathrm{m}$. (a) H45, (b) H60, (c) HIO0.

DCB: double cantilever beam.

does not influence crack kinking. The results for the sandwich DCB specimens with PES cores are very similar and not shown. The T-stress has a transition from a plateau region ahead of the crack tip (distance about a fraction of one core cell size) to reach a negative peak at the crack tip $(x=0)$. Although not shown, note that both $\sigma_{x}$ and $\sigma_{y}$ vanish for distances larger than about $0.5 \mathrm{~mm}$ ahead of the crack tip. For all the $12.7 \mathrm{~mm}$ thick foam specimens, the T-stress is negative at the plateau region. Thus, according to Coterell and Rice [5] the crack propagation should be directionally stable. For sandwich specimens with a thicker core $(25.4 \mathrm{~mm})$, Figure 9, the T-stress assumes positive values at a short distance in front of the crack tip (especially the H100 foam), which would indicate that crack kinking is a possibility. These results are in agreement with experimental crack growth observations (Figure 6).

\section{Maximum crack length for sandwich DCB specimen}

Figure 10 shows the compliance vs. the uncracked length (c) for sandwich specimens with $12.7 \mathrm{~mm}$ thick PVC and PES foam cores at a constant crack length $(a=50 \mathrm{~mm})$, calculated from equation (1). For short lengths, $c$, the compliance assumes very large values due to short foundation length. When the 

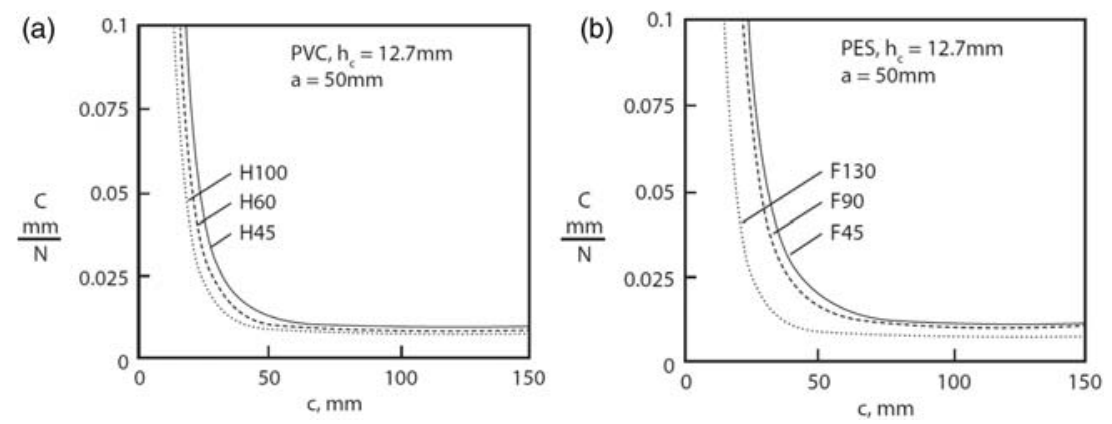

Figure 10. Compliance vs. uncracked length, $c$, for $12.7 \mathrm{~mm}$ thick DCB sandwich specimens at a crack length, $a=50 \mathrm{~mm}$. (a) PVC foam cores, (b) PES foam cores.

DCB: double cantilever beam; PVC: polyvinyl chloride; PES: polyethersulfone.

uncracked length is above a certain value, however, the compliance assumes a constant value independent of $c$. For stiffer cores, the transition into a constant compliance region occurs at smaller $c$ values (Figure 10).

For DCB specimens with a sufficiently long uncracked length, $c \gg a$, it is possible to approximate the functions $F_{1}$ and $F_{2}$ defined in equations (2) [8]

$$
\begin{aligned}
& F_{1} \approx 1+2 a \\
& F_{2} \approx 1+a
\end{aligned}
$$

Substituting equations (8) into (1) provides the following expression for such specimens $(c \gg a)$

$$
C_{\infty}=\frac{4}{E_{x} b h^{3}{ }^{3}}\left[2^{3} a^{3}+6^{2} a^{2}+6 a+3\right]
$$

The analysis of the test results is very much simplified if the compliance is represented by equation (9), i.e. the uncracked length, $c$, of the specimen should be greater than a certain limit, $c=c_{\min }$. The limiting value $c_{\min }$ can be obtained based on a $1 \%$ compliance difference criterion

$$
\frac{C \quad C_{\infty}}{C_{\infty} \leftarrow} \leq 0.01
$$

where $C_{\infty}$ is the asymptotic compliance, given by equation (9). $c_{\min }$, can be established from the hyperbolic functions in equations (2). The approximations, equations (8), require that

$$
\sinh (\ll) \cong \operatorname{sech}(\ll)
$$




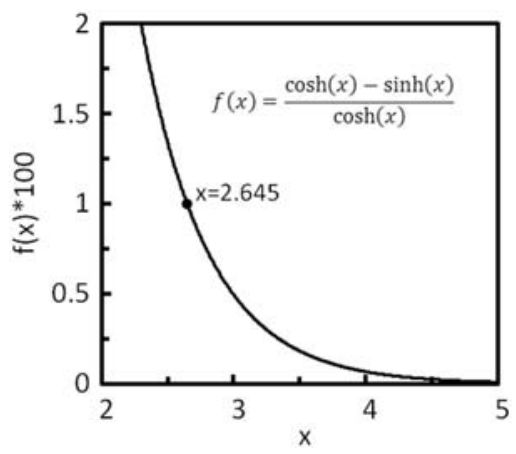

Figure II. Error function.

An 'error' function, $f(x)$ defined in equation (12), may be used to determine $c_{\text {min }}$

$$
f(x)=\frac{\cosh (x)-\sinh (x)}{\cosh (x) \leftarrow} \leftarrow
$$

This function is plotted versus $x$ in Figure 11. The results show that the error falls below $1 \%$ for $x \geq 2.645$. Replacing $x$ with $c_{\min }$ from equation (11) yields

$$
c_{\text {min }}=\frac{2.645}{(1 \% \text { definition })}
$$

This relation provides a lower limit on the uncracked length which is useful for specimen design and test considerations. Table 1 provides the limiting values, $c=c_{\min }$ for the DCB specimens considered in Figure 10. The results indicate that the crack may extend through about half the specimen length before the end effects start to dominate the response.

\section{Conclusions}

Analysis of a new test method to determine the mode I fracture toughness of polymer foam materials has been presented. The specimen consists of a rectangular strip of foam with an edge crack at the center bonded to two aluminum adherends loaded in a DCB configuration. A modified version of Kanninen's foundation model was developed for analyzing the compliance of DCB sandwich specimens. Finite element analysis was also conducted with the objectives to validate the compliance obtained from the foundation model and to analyze stresses in the crack tip region. Both the foundation model and the finite element model provided compliance predictions in agreement with experimental results for six types of DCB specimens over a large range of crack lengths. Furthermore, distributions of the non-singular T-stress were determined from finite element analysis for two core thicknesses to examine the stability of crack path. 
The T-stress results indicate that the crack path in specimens with a $25.4 \mathrm{~mm}$ thick core is directionally unstable, in agreement with experimental observations. For specimens with thinner cores, however, the T-stress results indicate stable growth, in agreement with the experiments that revealed stable collinear crack growth. A minimum uncracked length of the DCB specimen was determined which would be useful in an experimentation test program.

\section{Funding}

Support for this research was provided by the National Science Foundation (CMMI0824827) under a sub-contract from University of Delaware.

\section{Acknowledgments}

Special thanks go to Chris Kilbourn and James Jones of DIAB Desoto, Texas for providing the foam materials free of charge. Adrián Hernández thanks CONACYT (Mexico) for the scholarship support.

\section{References}

1. Maiti S, Ashby MF and Gibson LJ. Fracture toughness of brittle cellular solids. Scripta Metall 1984; 18: 213-218.

2. Zenkert D and Bäcklund J. PVC sandwich core materials: mode I fracture toughness. Compos Sci Technol 1989; 34(3): 225-242.

3. Viana GM and Carlsson LA. Mechanical properties and fracture characterization of cross-linked PVC foams. J Sandwich Struct Mater 2002; 4(2): 99-113.

4. Saenz E, Carlsson LA and Karlsson AM. Characterization of fracture toughness (Gc) of PVC and PES foams. J Mater Sci 2011; 46: 3207-3215.

5. Cotterell B and Rice JR. Sligtly curved or kinked cracks. Int J Fract 1980; 16(2): 155-169.

6. Williams ML. On the stress distribution at the base of a stationary crack. $J$ Appl Mech 1957; 24: 109-114.

7. Chen B and Dillard DA. The effect of the T-stress on crack path selection in adhesively bonded joints. Int $J$ Adhes Adhes 2001; 21: 357-368.

8. Kanninen MF. An Augmented double cantilever beam model for studying crack propagation and arrest. Int J Fract 1971; 9(1): 83-92.

9. Whitney JM. Structural analysis of laminated anisotropic plates. Lancaster: Technomic, 1987.

10. ANSYS 11.0. Swanson analysis systems. Houston, PA: ANSYS, 2007.

11. Hyer MW. Stress analysis of fiber-reinforced composite materials. Lancaster: DEStech Publication, 2009.

\section{Appendix}

\section{Analysis of the effective flexural modulus}

The analysis presented here follows the analysis of laminated beams presented by Whitney [9]. According to his analysis, the effective modulus, $E_{x}$, of a laminated 
beam is given by

$$
E_{x}=\frac{12}{d_{11} h^{3}}
$$

where $h$ is the thickness of leg $\left(h=h_{f}+h_{c} / 2\right)$, see Figure 12, and $d_{11}$ is the $m=n=1$ element of the bending compliance matrix given by

$$
[d]=\left([D]-[B][A]{ }^{1}[B]\right){ }^{1}
$$

where $[A],[B]$ and $[D]$ are the extensional, coupling and bending stiffness matrices defined in classical laminated plate theory, see e.g. Hyer [11].

$$
\begin{aligned}
& {[A]=\left[Q_{C}\right]\left(\begin{array}{ll}
z_{1} & z_{0}
\end{array}\right)+\left[Q_{f}\right]\left(\begin{array}{ll}
z_{2} & z_{1}
\end{array}\right)} \\
& {[B]=\frac{1}{2}\left[Q_{c}\right]\left(\begin{array}{ll}
z_{1}^{2} & z_{0}^{2}
\end{array}\right) \quad \frac{1}{2}\left[Q_{f}\right]\left(\begin{array}{ll}
z_{2}^{2} & z_{1}^{2}
\end{array}\right.} \\
& {[D]=\frac{1}{3}\left[Q_{C}\right]\left(z_{1}^{3} \quad z_{0}^{3}\right)+\frac{1}{3}\left[Q_{f}\right]\left(z_{2}^{3} \quad z_{1}^{3}\right.}
\end{aligned}
$$

Notice that for isotropic materials, $G=E /(2(1+v))$ where $v$ wis Poisson's ratio. $z_{0}, z_{1}$ and $z_{2}$ are the ply coordinates (Figure 12), given by

$$
\begin{gathered}
z_{0}=\frac{h_{f} h_{c}}{2} \\
z_{1}=\frac{h_{c} \quad h_{f}}{2} \\
z_{2}=\frac{h_{f}+h_{c}}{2}
\end{gathered}
$$

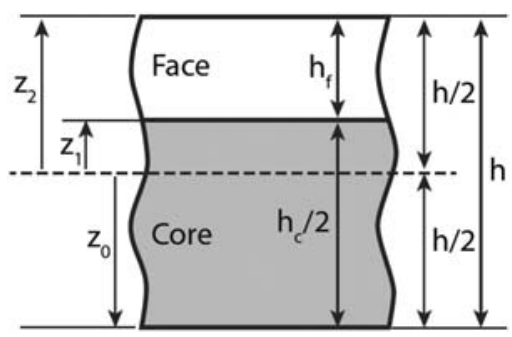

Figure 12. Cross section of upper leg of sandwich DCB specimen. DCB: double cantilever beam. 
$\left[Q_{c}\right]$ and $\left[Q_{f}\right]$ are the stiffness matrices of the core and face sheets (assumed isotropic)

$$
\begin{array}{rlrl}
Q_{11} & =\stackrel{E}{1 \quad v^{2}} & (18 \mathrm{a}) \leftarrow \\
Q_{12}=\triangleleft Q_{11} & (18 \mathrm{~b}) \leftarrow \\
Q_{22}=Q_{11} & (18 \mathrm{c}) \leftarrow \\
Q_{66}=G & (18 \mathrm{~d}) \leftarrow
\end{array}
$$

Post-print standardized by MSL Academic Endeavors, the imprint of the Michael Schwartz Library at Cleveland State University, 2014 